\title{
APOCALIPSIS: EL DESGARRO DEL DESEO DE UNA VIDA
}

\author{
Apocalypse: the Tear Up of the Desire of a Life
}

\author{
Susana Violante \\ (UNMDP, Argentina)
}

\begin{abstract}
Resumen
Al seleccionar este título intentamos reflejar la imposibilidad de generalizar los conflictos por los que atraviesan los distintos seres humanos y cuestionar algunas convenciones que la sociedad le ha asignado a "vivir una buena vida". Hemos de considerar que toda universalización plantea una consabida pérdida de singularidad, por esto pretendemos argumentar acerca de algunos "apocalipsis" que atraviesan las personas singulares -y también los grupos que luego se hacen sociales, generacionales, culturales, humano-universales- y algunas de las dificultades con que se enfrentan para revertir la situación. Una gran influencia está signada por lo que entendemos que puede ser llamada "desaparición o muerte del hombre", a decir de Foucault que, para nosotros, viene de la mano de una obligada y/o aceptada pauperización intelectual, una vuelta a las cavernas del pensamiento, donde nos hemos olvidado cómo pensarnos y cómo pensar a la humanidad toda. Preferimos comenzar analizando algunas cuestiones cercanas, antes de pensar en otras comunidades a las que nuestro análisis pueda ser transferido con muchas reservas, teniendo en cuenta que las situaciones son singulares, aunque a simple vista encontremos elementos comunes.
\end{abstract}

Palabras clave: Apocalipsis | Pauperización | Violencia.

\begin{abstract}
By selecting this title we try to reflect the inability to generalize the conflict by crossing the various humans and question some conventions that society has assigned to "live a good life". We consider that any universal poses a usual loss of uniqueness, so we intend to argue about some "apocalypse" that cut across individual persons and groups which are then social, generational, cultural, human-universal and some of the difficulties they face to reverse the situation. A big influence is marked by what we mean by the "disappearance or death of man", according to Foucault, that, for us, comes from the hand of a forced and / or accepted intellectual impoverishment, a return to the caverns of thought where we have forgotten how to think of ourselves and how to think all humanity. We prefer to start analyzing some nearby issues before thinking about other communities that our analysis can be transferred with many reservations, considering that the situations are unique, although at first glance find common elements.
\end{abstract}

Keywords: Apocalypse | Impoverishment | Violence. 


\section{1.- Pauperización intelectual}

En nuestro país, Argentina, encontramos que muchas personas y comunidades son invisibilizadas, negadas en su condición paupérrima, olvidadas y solamente recordadas por los mismos "olvidados". De estas personas no nos ha llegado ningún relato, sin dudas justificado por su erróneamente asumida incapacidad para la alfabetización y, en los casos en que han sido relatadas por otros, siempre se produce una pérdida en la narración, además de ser una realidad que ocultar. El filme de Buñuel ${ }^{23}$, que lleva por título Los olvidados, posiblemente sea una excepción por su maestría en dar voz a los que no la tienen. Su relato fílmico culmina con una escena que traspasa toda frontera de temporalidad aunque, no nos arriesgamos a generalizar en cuanto a cultura y religión con la esperanza de que haya alguna que no actúe de este modo. La historia narra, a grandes rasgos, lo acontecido entre una madre muy pobre y su hijo -que lleva por nombre, Pedrode aproximadamente 10 años de edad que, al ser rechazado por su madre busca trabajar para recuperar sus cuidados, al no ocurrir esto decide huir. Entabla una relación con un adolescente de su entorno que comete un asesinato y varios robos, de uno de estos robos culpan a Pedro quien decide denunciar al adolescente por el asesinato, por este motivo el adolescente mata a Pedro en el gallinero de la casa de una niña del barrio. La niña y su abuelo envuelven en unos trapos el cadáver de Pedro, a quien conocían, y lo llevan a un lugar alejado para tirarlo porque no saben qué hacer con él y no desean ser culpados de haber ejecutado esa muerte. En el trayecto se cruzan con la madre de Pedro que saluda con un cordial "buenas noches". Nadie dice nada, la madre no sabe lo que allí portan. Es una escena muy fuerte en símbolos, desgarradora, la de pasar por al lado del cadáver del hijo y no saber que está allí, porque lo ha desconocido en vida no puede reconocerlo muerto porque, además, busca a un niño que ella ayudó a morir y los esfuerzos del niño por vivir no fueron suficientes. El miedo es un fuerte elemento de pauperización, sobre todo si es generado por la desconfianza que se aplica a la palabra testimonial de un pobre, ladrón, marginal, junto al conflicto de saber que la desconfianza está instalada hacia todo "otro" que impide una comunicación interpersonal.

$\mathrm{Al}$ relato del filme, que podemos observar vivo en muchas zonas de nuestro país, agregamos como elemento de pauperización, por ejemplo, que los padres, o personas a cargo de niños, no saben cuándo tienen que llevar a sus niños al médico, ni siquiera cuándo tienen que ir ellos o que, tal vez ni siquiera saben que existen personas que pueden "curar" aquello que su "curador" no alcanza a sanar y van muriendo niños y adultos no solamente por inanición sino, muchas veces, por infecciones que se tratan con rudimentarias acciones como por ejemplo insertar una cebolla en un clavo oxidado con el que un niño se ha clavado, culminando con la amputación del pie del niño. Situaciones de alto riesgo favorecidas por la ingesta de sustancias tóxicas en alimentos que son retirados de contenedores en estado de putrefacción. Otras veces caen en manos de los que se creen que saben, que lo tienen todo organizado, que dicen que su industria favorecerá al "pueblo" propiciando un mayor empleo y matan. Estas industrias de muerte -por ejemplo la minería a cielo abierto-, son instaladas donde viven aquellos a quienes se les ha arrebatado la capacidad de pensar, de reconocer el peligro que, por ejemplo, beber agua de determinados ríos o arroyos en los que desembocan cantidad inconmesurada de residuos

23 Buñuel, Luis, Los olvidados, 1950. Considero que es una gran película y utilizo el adjetivo "gran" porque muestra muchas bajezas sin necesidad de actuarlas para el auditorio, no le hizo falta a Buñuel. Ha sido nombrada en 2003, "Memoria del mundo" por la UNESCO, nominación que se merece pero que invita a pensar en el porqué de la demora cuando el relato es una constante en nuestro mundo, la pobreza, el abandono, la utilización de los niños, las violaciones, los golpes, las muertes... en este caso en un barrio "olvidado" en México pero que encontramos en muchos barrios olvidados de muchos pueblos, ciudades, etc. 
tóxicos ${ }^{24}$, les provoca ya que, con el cianuro liberado se arrastran y potencian otros metales que amplían la cadena contaminante generando, no solo por el consumo sino por la inhalación, una cantidad de malformaciones en recién nacidos, adolescentes y adultos, muchos tipos de cáncer y muerte luego de un largo y penoso sufrimiento, o la muerte inmediata.

Desde el siglo XIX, existen emprendimientos mineros cuyos proyectos, aunque han sido aprobados por el Estado, no respetan los convenios correspondientes, por ejemplo la Ley de Glaciares que, además, mantiene en salvaguarda la vida de los habitantes que, muchas veces, no tienen la capacidad de defenderse de las agresiones que reciben, en terminología especializada. Los "poderosos" se escudan en el discurso del cuidado pero se niegan, por ejemplo, a beber el agua de los arroyos en los que vierten sus soluciones cianuradas. Personas a quienes otras personas inescrupulosas no valoran como tales. Nos resulta casi imposible no caer en frases maltrechas luego de ver los rostros y las deformidades de algunas personas a causa, entre otras muchas, de la falta de controles que no impedirían el enriquecimiento de algunos sino que protegerían a una minoría sin voz que viven una muy mala vida. Estas personas simbolizarían ese tercio que alguna de las plagas que relata el texto bíblico, mata.

Es probable que en el Siglo XIX se desconociera que el agua es un recurso con fecha de caducidad y si los glaciares son una importante fuente de agua para el planeta, es fácil advertir lo que este tipo de contaminación supone para el futuro de la vida, al menos hasta que el sol comience a enfriarse. El problema que se avizora como resultado de la complicidad y la impunidad de algunos hombres impíos, que el texto bíblico del Apocalipsis también relata, podría generar esos desastres no "naturales" sino promovidos inescrupulosamente de los que, la pobreza en todas sus manifestaciones, es uno de ellos. Basta con observar los rostros temerosos de recibir mayores males en muchas de estas personas cuando se las quiere ayudar. Aquellas que están más fortalecidas, comprenden que se pueden ejecutar acciones que modifiquen la situación en la que se encuentran e intentan involucrarse política o religiosamente para lograr mantener los que otrora fueron sus bienes naturales y que les han sido arrebatados en nombre "de la mejor cultura posible en el mejor de los mundos posibles". Aquellos a quienes el sufrimiento y la muerte desgarran de continuo, anulando toda posibilidad de concretar siquiera algo de lo que se habían propuesto para sus vidas, se sumergen en la penuria de la impotencia de no poder hacer. Y otros, no hacen porque son amenazados.

Estas personas están inmersas en los discursos de "otros" que les hace "creer" y les "convencen" acerca de la imposibilidad de la realización de sus personales utopías, porque solo unos pocos son los elegidos. Las consideraciones de "utopía" e "imposibilidades estructurales" son consideraciones que anulan la búsqueda de soluciones y de fortalecimiento para alcanzar aquello que ciertos grupos marginados desean, y con ello el posible riesgo de desbaratar los activos centros de poder, además de desvelar la impotencia de quienes dicen poseer soluciones. El utopismo se opone al conformismo y procura buscar soluciones donde aún el propio tiempo no parece haberlas encontrado. "Con qué ley condenarte si somos juez y parte todos en tus andanzas" canta Joaquín Sabina ${ }^{25}$.

La pauperización intelectual elimina la valoración de la vida, somete y subestima a las personas por una condición urdida por los sometedores.

24 Internet ofrece una gran cantidad de documentación al respecto. No es mi interés analizar particularmente esta situación sino simplemente enunciarla para poder teorizar sobre ella sin caer en cotidianos análisis éticos.

25 SABINA, Joaquín (1985). "Princesa” en el álbum Juez y parte 


\section{2.- Educación y violencia}

En nuestro intento de dar qué pensar incursionamos en un tema comprometido como es la relación entre "docentes" -en los diversos ámbitos educativos-, y los modos de violencia que en muchos centros se ejerce.

De las variadas manifestaciones de violencia, tendremos en cuenta las que se manifiestan en nombre de la ciencia o de la religión.

Muchas veces los medios de comunicación (hacemos mención a ellos por ser los que más llegan a las personas), hablan de "violencia estructural", terminología que consideramos de alto riesgo para designar aquello que no se analiza con la precaución que se debiera porque, si es "estructural" no se puede eliminar, por lo tanto, se haga lo que se haga, ella persiste con la atroz consecuencia de que las personas no se involucren sumada a la incapacidad de algunos especialistas que desplazan la responsabilidad que a cada ser humano particular le cabe en ella, a los propios involucrados. Esta significación representa una ceguera y falta de responsabilidad que impide el diálogo que posibilite la modificación de su propia y magra vida, mantenida por un sistema que ha estructurado la imposibilidad de satisfacer determinadas necesidades básicas.

Consideramos relevante referirnos a la violencia que se ejerce en algunas instituciones educativas. Ahora bien ¿̇por qué involucramos en este espacio a la educación? El proceso educativo ha sido concebido durante muchos siglos, pero posiblemente con más fuerza en los siglos XVII y XVIII, como la panacea del logro del paraíso en la sociedad, esperando como resultado la buena convivencia y la eliminación de la mala acción, ya fuera porque los libros sagrados lo proponen a través del miedo al castigo divino o por influjo de la mirada controladora, no ya de un Dios omnipotente, sino de un ser humano hacia otro, quitando intimidad, libertad y mundo. Lamentablemente no se ha logrado, ni desde la psicología con el mandato moral del súper-yo, ni desde la educación, que la persona controle sus deseos de poder y avaricia sobre otras personas. Ese deseo de ser "dios" y tener la influencia sobre los demás y la obediencia sin conflictos transfiere, desde un modelo educativo que obliga a instalar los modos del buen vivir establecidos al mantener prohibiciones que regulan el accionar humano. La gran pregunta: clas prohibiciones sirven? ¿Porque algo se prohíbe deja de acontecer?

Una de las acciones relevantes en un ser humano es la capacidad de observar y observarse ¿sabemos realizar esta acción? ¿El docente "observa”? o más bien ¿sólo mira y es incapaz de sospechar posibles consecuencias violentas en las acciones que acontecen ante su presencia o por su conducta?

Hallamos un conflicto en la relación Escuela/Familia, la primera no puede hacer lo que la segunda no hace, la segunda espera que la primera complete su imposibilidad. El diálogo de la primera sobre la segunda suele ser, en muchos casos, el de "decir" lo que la segunda ha de hacer para alcanzar la "felicidad" traducida en la educación de un niño que no moleste en la clase, de este modo dan muestra de no comprender los innumerables conflictos que la segunda enfrenta. Afortunadamente no podemos universalizar esta situación pero sabemos que acontece con más frecuencia que la deseada. Hay docentes que no encuentran el modo de hablar con las familias, no las observan, no logran sospechar sus penurias y las "tratan" desde un universal del criterio de "familia normal", basado en la experiencia familiar propia del "docente/hablante", o del relato bibliográfico, o han sido moldeadas para trabajar en condiciones ideales con estudiantes y familias "modelo".

Tampoco colaboran en la generación de conocimiento las autoridades en ninguna de sus jerarquías al no disminuir el número de estudiantes por curso, al no considerar la colaboración permanente de ayudantes en el aula, al permitir que personas con un título que no es el específico, ocupen la plaza de otras. La temible frase: "el aula no puede quedar vacía" refiriéndose a la carencia de titulaciones específicas y, en ellas la idoneidad y 
honestidad intelectual imposibles de determinar.

Hemos tenido la grata experiencia de contactarnos con educadores y directivos de instituciones que han podido observar estas dificultades y han procurado convocar a diversos especialistas para que observen el medio dificultoso en el que se desempeñan y, a través de los relatos y observaciones de ambos, buscar los modos de modificar alguna de las actitudes para que muchas familias logren desplazarse hacia un "mejor vivir" a partir de un "mejor relacionarse". Pero, como señalamos, no se da en todas las instituciones y, las que logran visualizar los modos para superar las dificultades, no lo pueden compartir, porque son situaciones singulares que se han analizados a partir de improntas profesionales también singulares.

Muchas acciones del quehacer docente han sido "naturalizadas" desde la costumbre de la permisión educativa, una de ellas es, por ejemplo la "competencia". Hemos escuchado que, para algunos docentes, la competencia es "algo natural en el hombre". Si analizamos esta frase hemos de comprender que, entender a la competencia como algo inherente a la naturaleza humana, derrama inmediatamente en la imposibilidad de destierro de la competencia, de las jerarquías, de la superioridad y de la subestimación, dejando al que "pierde" en el lugar del "pobre que nunca va a llegar a nada". Hay una expresión de "ira" que algunas veces los docentes promueven al hacer que los estudiantes compitan en lugar de proponer actividades para que se superen a sí mismos. Algunos docentes mantienen, por ejemplo, estas frases: "vos sos el mejor", "si te pegan pegá", "fulanita es para escuela especial", "menganito nunca va a llegar a nada", para aquellos niños, adolescentes y adultos que no han logrado cumplir con las expectativas del docente incapaz de variar los modos y temas de evaluación en el espacio llamado "la clase". De este modo muchas personas han sido subestimadas en sus capacidades arrebatándoles la posibilidad de alcanzar conocimientos complejos útiles para su vida y, el que no se adecua, es regañado, insultado, humillado. O por el contrario la demagogia educativa que hace "creer" que el estudiante "sabe" lo que no sabe. Corresponde mencionar que nos estamos refiriendo a situaciones corrientes en las que no media discapacidad mental alguna, sino falta de afecto, cuidados y alimentos, tanto por parte de la familia como de la institución, actitudes todas que debilitan la práctica docente.

La defensa y valoración de la profesión, la encontramos expresada en la capacidad de promover actividades que reconozcan las capacidades individuales e impulsen el fortalecimiento de las personas.

Nos preguntamos: ¿es válido hablar de "proceso de enseñanza-aprendizaje", cuando uno de los involucrados se instala en una mayor jerarquía? Pero esta frase se acepta como si fuera de avanzada y se defiende la designación de proceso de enseñanza-aprendizaje cuando al hacerlo, se está manteniendo una relación causal que oculta la tradicional concepción: docente (el que sabe y enseña)-alumno (el que ignora y aprende), esta frase mantiene la jerarquía de quienes asisten a una entidad educativa.

La educación a través de estas y muchas otras prácticas, es generadora de violencia al agredir desde el soporte de la ignorancia, de quien supuestamente "enseña" y ofrece materiales rígidos y predeterminados tomados de los proyectos emanados del Ministerio que determinan contenidos mínimos para una asignatura sin tener en cuenta las singularidades grupales, más que regionales, desconfiando de las capacidades docentes para elaborarlos, de este modo, pocas veces impulsan al pensamiento a un estudiante pauperizado y, cuando la vida cambia para algunas personas y deciden ser "otro", se dan cuenta que la sacrosanta institución educativa, los estafó. Como también han sido estafados muchos docentes en su capacitación como profesionales de la educación.

Tal vez la posibilidad siga estando, como decía Kant, en Sapere aude!!! Atreverse a saber para anular las demagogias educativas.

Las formas de ejercer violencia son muy variadas, sutiles o explícitas ya que no se 
limitan a los modos de agresión física de una persona sobre otra, contra el medio ambiente o contra los bienes personales o sociales que adquieren la característica del robo, asesinato, ataques a inmuebles, secuestros y denigrantes etcéteras.

\section{3.- El apocalipsis de los valores}

¿En la apertura de qué sello del apocalipsis se ha determinado aquello que se ha de valorar desde una incuestionable objetividad?

Tal vez uno de los conceptos más difíciles de analizar sea el del "valor" porque tiene que ver con la importancia que un grupo humano ha depositado en determinada "cosa" de la vida en vista a determinados intereses personales con validez universal. Estas valoraciones no son ingenuas ya que se dirigen a mantener prejuicios que no son de peso para nuestra vida y se le otorga poca importancia-valor a la propia vida. Las personas hablan de "flagelos", de "crisis de valores", pero no se analiza por qué se los mantiene, por qué se deposita la vida en ellos. Hay vestiduras e investiduras desgarradas pero no abundan los análisis que permitan comprender la angustia en que muchas personas viven por no poder valorar su desgarrada vida.

Este escrito pretende argumentar por qué los "flagelos" se mantienen, pero: ¿qué personas pueden llegar a leerlo? ¿De quiénes nos puede llegar su crítica para, a su vez, acercarnos a aquellos ámbitos que viven en un continuo apocalipsis?

Las espeluznantes variedades de tóxicos que producen dependencias y muertes, las variedades de pobreza, las variedades de "envidia" porque "el otro tiene lo que yo deseo", porque no se ha trabajado profesionalmente para aceptar la diferencia de deleite entre las personas y comprender que no sabemos escuchar sino solamente "hablar", emitir sonidos que muestran como un "valor" aquello que produce degradación y muerte, que desearlo ha de ser una decisión personal y no una imposición del deseo. Se transfieren modelos de vida con valor objetivo, entonces sentimos que estamos en medio de una sociedad que valora y mantiene esas adicciones y esos fracasos porque a algunos les sirven para seguir dominando y seguir destruyendo la posibilidad de equiparar oportunidades de fortalecimiento personal. Encontramos que hay un odio avalado por múltiples instancias sociales que "hablan" de responsabilidad social e individual pero que interfieren en su consecución. Se busca que la sociedad funcione a base de tratos y contratos que no sirven para nada porque anulan a las partes. Un trato se hace sobre la base de la renuncia de aquello que supuestamente impide el "equilibrio" y termina siendo desobedecido por considerarlo una "injusticia" y es muy probable que lo sea porque no se ha mediado en los deseos de los oponentes en el conflicto y en la anulación de las causas personales y, tal vez, por esto no se cumple porque no se desarrolla una "cultura" de la convivencia, sino de la renuncia. Los involucrados en el pacto no debaten la importancia de cada uno sobre la vida sino que luchan por imponer su propio modelo.

Por lo que vamos señalando y por lo que falta, consideramos que el apocalipsis es la arbitrariedad en el ejercicio de la justicia porque "la" justicia como tal no es ciega ni sorda ni muda. ¿Cuándo podemos afirmar que es "injusto" aquello que padecemos, si la justicia es determinada por intereses personales sin importar el de los otros? ¿En qué espacio discursivo se utilizan términos como "justo", "injusto", "justicia", "injusticia"? Los nombrados conceptos se han ido reformulando y han dado inicio, por modelo repetitivo, a la "legislación" en tanto regulación y ordenamiento deseable para los distintos usos y costumbres. Se pide objetividad en los valores para que pueda haber objetividad en la justicia pero el debate sigue abierto porque esa objetividad es ficticia. No puede legislar sobre la domesticación, los maniqueísmos, lo femenino y lo masculino, el padecimiento del mal, los "beneficios considerados naturales", las imposiciones. Por esto "justicia" (iustiťa) 
en la teorización tradicional se toma como la concepción que cada época y civilización tiene acerca del sentido de sus normas jurídicas. Los miembros de la sociedad la comprenden como un valor determinado y como un bien común nacida de la necesidad de mantener la armonía entre sus integrantes a través de un conjunto de pautas y criterios que establecen un marco adecuado para las relaciones entre personas e instituciones, autorizando, prohibiendo y permitiendo acciones específicas en la interacción de individuos e instituciones. De acuerdo con el diccionario Iustitia es una virtud; Ius es la ejecución de la virtud. El gran conflicto surge cuando sostenemos que justicia es otorgar a cada uno lo que se merece, lo justo. Pero en el reparto de "justicia”, se cometen "injusticias" porque ¿cuáles son las singularidades que en el reparto no se contemplan?

Lo que hemos señalado en el transcurso del escrito hace aparecer sucesivos dilemas porque no hallaremos modelos universales de resolución sobre los conflictos sino que, cada vez es más notorio, el reconocimiento de la necesidad de observar los casos particulares en su manifestación delimitada. No podemos abandonar el análisis del valor sin señalar en una pregunta: ¿quién nos ha llamado a ser los salvadores de una buena parte de la humanidad, mesías con toscos estatutos buenos solamente para engañar al vulgo?

\section{4.- La utopía del trabajo que ennoblece}

La cultura del trabajo no es tan antigua como solemos pensar o como la mayoría de los empresarios y/o directivos, quieren que pensemos para "tener" esclavos legales. Pensemos que en los monasterios medievales y, posteriormente, en países como España, Inglaterra, Portugal... no estaba bien visto el trabajo porque sólo trabajaban los esclavos y los pobres, una concepción que se importa y permanece en el tiempo ya que ahora mantenemos el esquema. Nos cuesta mucho hallar instituciones que no estén constituidas por un determinado poder para esclavizar. Se dice que "El trabajo dignifica" pero no se dice que es a aquel para quien se trabaja. Encontramos un exceso de violencia porque muchas veces en el trabajo hay que ser hipócrita, débil y dominado y esto vale para cualquier género humano. No basta con que se pague bien, porque un buen salario no elimina el "acomodo" ni que algunas instituciones estén formadas por "amigos".

¿Qué puedo hacer como persona, como sociedad, como institución? La vida es una propiedad única ¿propiedad única? ¿Cuando cualquiera se apodera de ella?

Foucault sostiene

"No es exactamente ni la energía de los fuertes, ni la reacción de los débiles; es más bien esta escena en la que se distribuyen los unos frente a los otros, los unos por encima de los otros; es el espacio que los reparte y se abre entre ellos, el vacío a través del cual intercambian sus amenazas y sus palabras" (Foucault, 1980:16).

"La relación de dominación tiene tanto de «relación» como el lugar en la que se ejerce tiene de no lugar. Por esto precisamente en cada momento de la historia, se convierte en un ritual; impone obligaciones y derechos; constituye cuidadosos procedimientos. Establece marcas, graba recuerdos en las cosas e incluso en los cuerpos; se hace contabilizadora de deudas. Universo de reglas que está destinado a satisfacer la violencia. Sería un error creer que termina por renunciar a la violencia y acepta suprimirse a sí misma en las leyes de la paz civil. La regla, es el placer calculado del encarnizamiento, es la sangre prometida" (Foucault, 1980:16).

Repetición meticulosa de la violencia en nombre del compromiso, de la necesidad de aceptación de la ley que conduce a la perversión.

"El deber, tiene su centro de emergencia en el derecho de obligación y, en sus 
comienzos como todo lo que es grande en la tierra, ha sido regado de sangre".

Las reglas no sustituirán para siempre a la guerra y/o a la violencia; instala cada una de estas violencias en un sistema de reglas y va así de dominación en dominación. Y es justamente la regla la que permite que se haga violencia a la violencia, y que ninguna otra dominación pueda plegarse a aquellos mismos que dominan. En sí mismas las reglas están vacías, violentas, no finalizadas; están hechas para servir a esto o a aquello; pueden ser empleadas a voluntad de este o de aquel (Foucault, 1980:17).

\section{5.- Alguna teorización}

La historia reciente es una copiosa fuente de situaciones que dan cuenta de aquellos seres humanos que han hecho cualquier cosa sin cuestionamientos para lograr sus nefastos objetivos en nombre de la "salvación" de la humanidad entera a pesar de la negativa de muchos humanos. Pensamos en lo que fue Sarajevo, hermanos contra hermanos, contra padres, madres, primos, amigos... y lo que vivimos en nuestra vida cotidiana, en Argentina y en tantos otros países, ciudades, pueblos, barrios, familias, cuando no existe la posibilidad para el diálogo en ningún ámbito de la vida, desde la familia hasta los centros de profesionalización. Las personas se instalan en la verdad que profesan y no escuchan otras opciones, repiten el mismo enunciado queriendo mostrar que poseen la verdad absoluta, dogmática, acompañada de un discurso que afirma, a la vez que niega, lo que ha sido dicho porque se quedan sin argumentos de defensa de su dogmatismo y no pueden aceptar su confusión.

En casos de conflictos se busca al "culpable” y se pregunta “¿Quién lo inició?” y la respuesta es "él”, o "ellos", siempre es el otro, o los otros, pocas veces se comparten las responsabilidades. Ahora bien cimporta quién pudo haber iniciado el conflicto cuando ninguna de las personas involucradas reconoce haber colaborado en su inicio? Un argumento que podemos ofrecer al respecto es que "sí, importa" saber quién lo inició cuando este "hacerse cargo" permite abrir el espacio de diálogo para la resolución y, "no importa" cuando el deseo, la voluntad, el interés están abocados a la resolución o detenimiento del mentado conflicto. Desde la ingenuidad pareciera que tendría que existir un mundo de niños o ancianos sin capacidad de confrontación armada, porque, pareciera que es, precisamente en la franja de la "mediana edad" donde se "proyectan los desastres" y serían quienes idearían las sofisticadas y apocalípticas formas de la muerte. Pienso en las dictaduras militares y en las feroces conflagraciones y en su poder anihilador de voluntades, pensamiento y decisión. Se comienza por un hecho insignificante para que sea la llama de la discordia y se impide el acto dialógico que lo desvanecería porque hace falta dar rienda suelta a la violencia. Por el acto insignificante se arriesga la vida y se mata por el sinsentido.

"Existe Auschwitz, por lo tanto no puede existir Dios", expresa Primo Levi en su entrevista con el periodista Ferdinando Camon, a lo que Levi agrega: "No encuentro una solución al dilema. La busco, pero no la encuentro" ${ }^{26}$.

\section{6.- La filosofía y los conflictos}

Se ha insistido mucho en este artículo en que algunos problemas planteados se dilucidarían a través del diálogo. Un procedimiento de reflexión que se utiliza poco porque requiere de la escucha para explicar las diferencias de perspectivas ante un tema y posibilitar que esas perspectivas provoquen a su vez otras que sean más amplias que

26 Extraído de Grüner, Eduardo (2001): "El dilema de Job, o lo sublime en Auschwits”. 
aquellas y que permitan que los sujetos en conflicto encuentren un punto de entendimiento a partir del cual comenzar a convivir. Por el contrario, encontramos que se busca el diálogo para imponer verdades que son mentiras y, de este modo, el espacio de debate se niega para que la confluencia de observaciones no alcance a desenmarañar la consecución de los intereses personales. La voluntad de saber y de congeniar, a decir de Foucault, deja paso a la voluntad de verdad, por esto mismo es imposible siquiera introducir perspectivas disímiles. Esta presunción nos permite reconocer la imposibilidad de que, aquellas personas en estado crítico logren encontrarse con especialistas que no comploten con los poderosos y que desvelen el funesto secreto en la mediación de los conflictos que van surgiendo y, en consecuencia, que el otro sea visibilizado, como buscamos, en tanto resultado de un ejercicio reflexivo que descentre el poder y tenga en cuenta a ese otro yo que no existía en "mi" mundo, a quien se castigaba, embaucaba, avasallaba, condenaba, mataba. Insistimos en la modificación de actitudes para que las personas a las que se les ha arrebatado la capacidad de pensar, de tomar decisiones, dejen de "creer" que es la vida que les tocó vivir, porque "algo habrán hecho"; dejen de cargar con un pecado heredado, ir de apocalipsis en apocalipsis, que transiten el sendero impreciso de un proyecto que tenga en cuenta las valoraciones de los grupos marginados y auto marginados y que, desde ellas, permitan que otras valoraciones aparezcan.

El filósofo que ha de reflexionar sobre estas cuestiones, ha de favorecer el encuentro entre pensamientos, conceptos y posibilidades de pensamiento.

Nuestro entorno no alaba la responsabilidad ante el error, ni la prudencia de saber que al tomar decisiones, en ellas, va unida la posibilidad de equivocarse, la posibilidad de rectificar, de ofrecer el espacio para el desacuerdo y para la argumentación.

\section{7.- Apocalipsis bíblico}

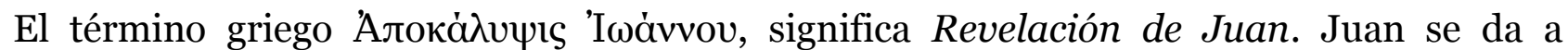
conocer en el mismo libro y nos informa que lo escribe estando en la isla de Patmos, $\mathrm{A}^{27}$, 1:9. Las posibles condiciones políticas de finales del siglo I y principios del II, en que se sospecha que fue escrito, son las persecuciones romanas a los cristianos en tiempo de Domiciano. Si bien el Apocalipsis sería un mensaje simbólico, lo encontramos muy directo en tanto mensaje de tolerancia y fortaleza para que los cristianos mantengan su fe en Jesús/Dios. El escrito fue aceptado por decreto del papa Dámaso I, en 382 so pena de ser excomulgado aquél que se atreviese a dudar de su veracidad y fue confirmado en el Concilio de Hipona (393) y en el de Cartago (397), luego de la aceptación por Constantino, de la religión cristiana como religión del Imperio ${ }^{28}$.

Las consideradas profecías simbólicas, en relación con el futuro al que debe someterse quien desobedezca las leyes divinas, muestra la necesidad de un intérprete aceptado por el centro de poder religioso que dirá lo que cada una de ellas significa y cómo el ser humano puede resguardarse de padecerlas cumpliendo el mandato divino revelado por un hombre al resto de los mortales, una obediencia que salva el alma. Desde antiguo se sabe que todo símbolo necesita ser interpretado porque, en tanto conjunto de signos, su significación se pluridimensiona negando la posibilidad de alcanzar la univocidad del sentido o significación. Pero este comentario sólo nos permite argumentar por autoridad que nuestras sospechas no son infundadas pero no aportan al tema nada sustancial. Lo que nos interesa resaltar es, por ejemplo, que un libro en el que cree una multitud de individuos, permite avalar las desgracias sufridas por una multitud de personas que se

27 Apocalipsis, en adelante: A.

28 No obstante hubo pensadores dentro de la misma Iglesia que lo han rechazado, por ejemplo Dionisio de Alejandría o Eusebio de Cesarea y tampoco aparece nombrado por Gregorio Nacianceno. 
encuentran entre el tercio a ser destruidas. El Apocalipsis, con su interpretación abierta, nos permite señalar que no es solamente los siete sellos que aparecen en A, 5:1-8:6, o las siete trompetas, A, 8:7-14:20; el relato de las plagas que representan el castigo divino y que la "moral negociada" - mantener la fidelidad a Dios a cambio de la salvación eterna-, no es suficiente para detenerlas, A, 15:1-15:21; o la terrible visión de la destrucción de los enemigos de Dios, A, 17:1-20:10; para culminar en el triunfo de esa moral negociada en A, 20:11-22:5. Ya que, quienes sirven a Dios, no tienen por qué temerle, más allá de las plagas que puedan sufrir, serán salvos. El Apocalipsis fortalece la hipótesis de ser bueno y obediente por miedo a un castigo que, por ser divino, no se puede eludir.

Así mismo encontramos que hay fragmentos que indican la responsabilidad de otras personas en las "plagas", "fuegos", "terremotos" y "muertes" que asolan a los individuos solamente por hallarse en el tercio a destruir. Aunque la pregunta ¿Qué he hecho yo para merecer esto? tiene una mínima impronta de nulidad, gran parte del escrito sagrado busca que el hombre se sienta culpable de un castigo divino y no reflexione acerca de su responsabilidad en la desgracia de otros congéneres o que no halle a los responsables de sus desgracias.

Dios manda amar al prójimo, pero sólo al prójimo cristiano, católico, romano, el resto de los humanos que tienen otras creencias no es "prójimo" y merece ser destruido, pero no por estas catástrofes del Libro, sino por aquellas que las personas inescrupulosas han preparado para hacer desaparecer a seres humanos que no son importantes para su avara "industria", cualquiera que ella sea y que necesite de seres humanos para llevarse a cabo.

Si bien el objetivo de la profecía es llamar a la reflexión y a la fe en Jesucristo como Salvador, rescatamos algunas frases que llevan a la reflexión, aunque incremente la atadura a los prejuicios con que se ha atormentado al ser humano en nombre de Dios indemostrable-, que ama a los hombres a través de terribles castigos.

Hay un orden entre capítulos y versículos que no modificaremos para realizar un breve análisis que colabore en lo que venimos señalando. Mateo 16:3, evoca como un pensamiento de Jesús: “¿Sabéis discernir el aspecto del cielo, pero no podéis discernir las señales de los tiempos?”, tal vez no sea ingenuo pensar la frase en clave de la observación de lo que ocurre a nuestro alrededor y los discursos de debilitamiento para la anihilación: Los movimientos neo-nazis. Palestina e Israel; industria farmacológica; la subestimación de la cultura para justificar una guerra o una ocupación; la chatarra espacial y las vigilancias "satelitales"; la injusticia de la que no podemos determinar sobre qué valores de "justicia" se determina; los alimentos producto de modificaciones genéticas; los bancos mundiales; las organizaciones mundiales; las ONG y todo aquello que, inventado para el bien de la humanidad, reditúa a unos pocos administradores de intereses.

En varios espacios del Libro se repite la necesidad de probar al hombre, probar su, fidelidad, probar su creencia y obediencia incondicionales; el hombre tiene que creer pero dios no puede creer en el hombre. De este modo hemos copiado el mandato para probar fidelidades. El hombre tiene que sufrir los más grandes pesares para ser probado y dice: "yo reprendo y castigo a todos los que amo" A, 3, 19.

La "fe" es definida como un don de Dios que ilumina las almas de los seres humanos para reconocer a Dios en cada una de ellas y comprender que, cuanto sucede a la persona, es gracias a esa luz infusa en el intelecto. No obstante al no ser posesión de todos esa "luz", permanece sin clarificar el "mal", aunque Dios no lo pueda ejecutar, el Apocalipsis nos muestra cómo es su mandato y cómo castiga a quien no obedece: entonces ¿́castigar a quién no obedece, es un bien? Esta última acción, castigar al desobediente, cuando se realiza en nombre del "bien" amparado en la "confianza", no suele verse como un "mal". La "caridad" cristiana impulsa al ser humano a velar por otros seres humanos a partir del amor a Dios. Entonces ¿si no amamos al Dios judeo-cristiano no amamos a nuestro 
prójimo? ¿Los budistas no aman a su prójimo? ¿Los musulmanes, tampoco? ¿Los mayas? ¿Los Incas? ¿Los aztecas? ¿Los ateos? que no han tenido la "gracia" de ser partícipes del Ser del Dios cristiano que es Amor. Se podrá criticar negativamente esta explicación diciendo que no comprendo lo que significa el "amor a Dios", si se dice eso no se está comprendiendo que, si hay una significación ecuménica, está en invertir los términos, porque no se trata de "amar al Dios cristiano" para ejercer la "caridad", sino "amar" a Dios cuando se comprende que "Dios" es "otro", cualquiera sea "otro".

Es digno reconocer que, tanto el cristianismo como otras formas religiosas, intentaron instaurar modos de proceder para lograr la consecución de un mundo mejor donde la esperanza se realizara, pero fracasaron y la esperanza se transformó en utopía aunque, por propia definición, sería impensable considerar que no cometer el mal "es" imposible, porque iríamos contra la "esperanza" de salvación donde el desaliento no tiene cabida.

La muerte preocupa al ser humano, pero para algunos será concebida como salvación. El capítulo 4 de Apocalipsis enuncia las cosas que "sucederán después de estas" y en 4:3 se habla del "sentado" y yo prefiero al que "camina" porque busca inquieto aquello que no posee y tal vez nunca poseerá. Las seis alas de los seres vivientes del apocalipsis están llenas de ojos ciegos, ojos que no pueden ver el deseo de vida de los hombres. En el capítulo 5 se nos informa que es el sentado quien tiene un libro sellado con 7 sellos. Según se relata, solo el cordero inmolado es capaz de tomar el libro y abrir sus sellos. Y, a partir del capítulo 6, comienza la apertura de los sellos. Del primero sale un caballo blanco montado por uno con arco y corona que fue enviado para vencer, del segundo sello sale un caballo bermejo (6:4) el que lo monta tiene el poder de quitar de la tierra la paz y que se maten los unos a los otros, por eso lleva una gran espada. En 6:5 se abre el tercer sello del que sale un caballo negro, el que lo monta tiene una balanza en la mano. Se abre el cuarto sello y (6:8) sale un caballo amarillo, el que lo montaba tenía de nombre Muerte y le seguía el Hades y también tenía el poder de matar con la espada, con hambre y con las fieras de la tierra. En 6:9 se abre el quinto sello y ahí aparecen las almas de los que fueron muertos en nombre de Cristo, pero tienen que quedarse allí hasta que se reúnan con todos aquellos que falta que mueran por Cristo. 6:12 se abre el sexto sello donde surge un terremoto, el sol se vuelve negro y la luna sangre y las estrellas cayeron sobre la tierra. Capítulo 8:1, se abre el séptimo sello aparecen siete ángeles a los que se les dan siete trompetas y también hubo fuego, truenos, relámpagos y un terremoto y los siete ángeles comenzaron a tocar las trompetas, de uno en uno. Sonó la primera y hubo granizo y fuego mezclados con sangre; al sonar la segunda una gran montaña de fuego cayó al mar y el mar fue fuego y sangre y murieron los peces y se destruyeron las naves. Del tercer ángel suena la tercera trompeta y una estrella cae del cielo sobre una tercera parte de los ríos y la estrella se llamaba Ajenjo y murieron hombres y animales por que las aguas se tornaron amargas como el ajenjo. Suena la cuarta trompeta y la tercera parte del sol es herida y la tercera parte de las estrellas y de la luna para que se oscurezcan en sus terceras partes y no hubiese luz en la tercera parte del día y que esa tercera parte fuese noche. En el capítulo 9 suena la quinta trompeta cae del cielo una estrella y hace un gran pozo como un abismo y sale humo y del humo pestes y comienzan las pestes de langostas que solo hieren a los hombres "que no llevan el sello de Dios en la frente", pero las langostas mataron solamente durante cinco meses.

Y nosotros, que aquí veníamos pensando en que hubiese sido muy acertado que se dijera que esa visión era metáfora de humanos a quienes darles el nombre de aquellas personas que matan impiadosamente a aquellos que no llevan el sello que certifique que son siervos de sus empresas y los muertos por el ensayo de medicamentos, o la ingesta de agua envenenada con cianuro, o invisibilizados y dejados sin voz para poder hablar en su nombre y continuar en la avara empresa de muerte y prestigio surgido de esas muertes, 
encontramos un relato admirable en su metáfora, A, 9: 7: "El aspecto de las langostas era semejante a caballos preparados para la guerra; en las cabezas tenían como coronas de oro; sus caras eran como caras humanas; (9:8) tenían cabello como el de mujer; sus dientes eran como de leones; (9:9) tenían corazas como de hierro; el ruido de sus alas era como el estruendo de muchos carros de caballos corriendo a la batalla; (9:10) tenían colas como de escorpiones y también aguijones; y en sus colas tenían poder para dañar a los hombres durante cinco meses; (9:11) y tienen por rey sobre ellos al ángel del abismo cuyo nombre en hebreo es Abadón y en griego Apolión".

Sexto ángel y secta trompeta, desatan a cuatro ángeles a fin de que maten a la tercera parte de los hombres a través de jinetes que de su boca salía humo azufre y fuego.

Nos resulta llamativo el relato de (9:20) por favorecer la adoración iconoclasta. Allí se menciona que los hombres que "no habían sido muertos, no dejaron de adorar a los demonios ni a las imágenes de oro, de plata, de bronce, de piedra y de madera, las cuales no pueden ver ni oír ni andar y que esos hombres no se arrepintieron de sus homicidios, de su hechicería, de su fornicación y de sus hurtos. Y esto hubiese seguido sino quedara un lugar de misterio porque una voz pidió que se sellara el séptimo sello y que no se diera a conocer ni por palabra ni por escritura su contenido. De este modo cuando el séptimo ángel toque su trompeta el misterio de Dios se consumará. Pero al final suena la séptima trompeta afirmando que todos los reinos serán de Dios y de Cristo que reinará por los siglos de los siglos. Muchos terremotos!!! Miedo, mucho miedo...

Es muy interesante en 13:15 como "la bestia" obtiene vida y mata a todo el que no la adore, siendo el número del nombre de la bestia 666. Pero Dios castigará con el tormento del fuego y el azufre a todo aquel que esté marcado por la bestia, o sea, que tenga el número de su nombre en la frente... Y ya vimos que en otro capítulo y versículo anterior se mataba a todo el que no llevase el sello de Dios y aquí, como corresponde se mata a quien lleva el sello del demonio.

En el capítulo 15 aparecen otros siete ángeles con siete plagas en las que se consuma la ira de Dios ¿puede Dios sentir ira cuando es perfecto?

El capítulo 17 relata sobre la gran ramera con la que han fornicado los reyes ¿̇cuál es hoy la gran ramera? ¿Con quién fornican los indeseables que ignoran a los pueblos? ¿Qué espacio geográfico es la Babilonia, madre de todas las rameras? ¿Cuántos espacios, ciudades, se pueden adueñar del título? Y así lo dice en 17:15 "Las aguas que has visto donde la ramera se sienta, son pueblos, muchedumbre, naciones y lenguas”. Por supuesto que después de todo esto vendrá un mundo limpio y gozoso para quienes creyeron y obedecieron sin pensar.

\section{8.- ¿Se puede concluir?}

Este artículo no tiene conclusión porque apenas comenzó. Hablamos mucho de los pauperizados intelectualmente, una minoría sin voz, pero también hemos de señalar que suele utilizarse el padecimiento para lograr cierta impunidad que permita, en nombre de la pobreza, el dolor, la desinteligencia, cometer acciones que manipulan a otras personas y, de este modo, encontramos a la agresión mutua como forma comunicativa.

Todo lo que no se nombró es lo que puede estar dicho por otros artículos. Todo lo que queda por decir, no es por ignorancia sino por no ser recurrentes, aunque estos ejemplos no basten.

Que no se lo valore de pesimista este artñiculo, porque el pesimista no muestra para modificar, sino que se lamenta y deja todo como está. Es más bien el nihilismo optimista, de Nietzsche tal vez, que observa señala y busca cómo superar esta impronta que, por estar inmersos en ella, nos paralizan las mil salidas del laberinto. Quisiéramos que 
la salida elegida fuera la correcta, pero no siempre es así y nos atormentamos porque no lo es, en lugar de correr hacia otra puerta, y otra, hasta hallar la salida.

Percibo el camino de nuestra vida hacia el final del filme de Buñuel: quien lleva nuestros despojos nos saluda amablemente como cualquier otro día aprovechando nuestro desconocimiento y nuestra incapacidad de indagatoria y sospecha.

\section{Bibliografía}

FOUCAULT, Michel (1980): Microfísica del poder. Madrid, Las ediciones de la Piqueta. Traducción de Julia Varela y Fernando Alvarez-Uría.

GRÜNER, Eduardo (2001): El sitio de la mirada, Buenos Aires, Grupo Editorial Norma. La Santa Biblia (1980): Madrid, Ediciones Paulinas; traducida de los textos originales, equipo de revisión Antonio González Lamadrid. 